\title{
Holistic Visualization Impact on Iranian Charity-Affiliated Teen Learners' Oral Proficiency
}

\author{
${ }^{1}$ Parhoon Rajeian, ${ }^{2}$ Alireza Ameri, ${ }^{1}$ Ghafar Tajalli \\ ${ }^{1}$ Islamic Azad University, Department of Foreign Languages, Science and Research \\ Branch Fars, Iran \\ ${ }^{2}$ Islamic Azad University South Tehran Branch
}

\begin{abstract}
Holistic visualization considers pupils, their needs, and the challenges they face, in their lives which can surface through oral proficiency. The present study aimed to scrutinize whether oral proficiency can be enhanced by asking students to visualize different things and talk about their feelings freely. The Participants were ten male and female charity affiliated students. Qualitative research and Ethnography in particular, was the main methodological orientation herein. And data was collected and generated through major techniques such as observation, students' portfolios (containing their drawings, and English writings) creating images, diagrams, animations, dramas, and interviews. Researchers-designed oral tasks for assessing learners' oral proficiency were part of the pedagogical agenda for this study whose crucial point was to ask students to think they were someone or something else so that it might improve their oral proficiency via enhanced power of imagination. In these activities participants attempted to express themselves without being worried about making mistakes in their speaking and it engaged their imagination and creativity and facilitated their learning. Finally, through these activities participants envisioned their desirable future unlike their first vision at the very beginning of the class and they could develop an integrated vision. Marginally, it engaged learner's linear thinking and intuition. The result showed that holistic visualization approach and its manifestation in oral proficiency would be justifiable for Iranian EFL charity teen participants whose social position has been neglected. And, based on the data we analyzed holistic visualization had an influence on oral proficiency for this charity institute students.
\end{abstract}

\section{Introduction}

Some scholars insist that education should be seen as the art of growing the moral, emotional, physical, psychological and spiritual dimensions of the learners. For instance, [4] noted that holistic education is rooted in perennial philosophy, meaning, in [8] terms, that "all life is connected in an interdependent universe", and therefore it aims to embrace all aspects of personal learning and growth. It also can be the result of different theories that attempt to stress on spiritual dimension. The concept of spirituality is what largely distinguishes this approach from other approaches to education. It means an 'inner core' of every person that lies beyond the physical, social and other sources of personality. It is the essence of holistic education, also a key for the interconnectedness of the human beings with the community they live in [14]. Holistic education indicates that each person has to find his or her identity and goal in life through connections in the natural world. [8] stated that holistic theory attempts to align education with the fundamental realities of nature that is dynamic and suggests interrelatedness of phenomena (p.4). Its purpose is to help people have enthusiasm for learning, as well as have reverence for life. Within holistic view, collaboration is more important than competition, and teachers let learners feel selfconfident. It considers pupils, their needs, and the challenges they face in their lives. On the other hand, one of the sizeable problems in learning is to handle abstract concepts for which learners do not have a concrete model in their everyday life. To accomplish the foregoing proposition, [1] acknowledged that providing interactive visualizations as extra material for the learners is a suitable way to concretize the subject in the beginning. Visualization is an interdisciplinary activity which involves different ideas about different subjects.

Although there has been little research done, at least in Iran, to examine and promote oral proficiency of students, it is by oral interactions that one can create their impressions of who they are and what they think or believe in. So considering all these, having the ability to apply the linguistic knowledge with the purpose of conveying feelings or thoughts is essential for students. Allen et al. cited in [16] articulated that learners' output is often limited to one or two words in the target language, and in order to assist them in talking more, teachers may 
create an interactional environment, and produce activities that require learners to communicate their own meaning [11]. In order to encourage learners to talk, teachers can ask open-ended questions, such as, why do you think? Or why do you think so? As long as holism - a treatment both for mind and body - is concerned, a group of charity learners are invited as the participants in order to suit the purpose of this study. In order to carry out an ethnographic observation for a thorough understanding of what is happening to these participants with their exceptional beings who have been neglected and tormented from many perspectives, the researchers are both a participant in the life of the setting and an observer who can describe the experience at the same time. One of the major things that could be done herewith is to observe whatever that happened in the class and narrated them adequately.

As a consequence, operationalizing holistic visualization and its manifestation in oral proficiency would be practical for Iranian EFL charity teen learners whose social position has been ignored.

\section{Statement of the Problem"}

As an experimenting teacher of English, the researchers had always been wondering if there were certain ways in which one could enhance and improve the quality and status of English as a foreign language, particularly oral proficiency in Iran. Teaching English in Iranian educational context is often restricted to pre-planned curriculum and learners are treated almost as empty vessels to be filled fully with the information they receive from their teachers who have all-out authority and control in the classroom. This helped the researchers realize the important facts that they were often unrecognized and overlooked in educational contexts at least as far as she could observe. As [8] in his book articulated, knowledge is not static but instead it relies on our ability to interpret and make meaning and this cannot happen unless knowledge and imagination are interconnected. By linking knowledge and imagination we enliven knowledge and ground the imagination in specific context (p.4). Having said all the above, through visualization as one of the techniques of imagination, both interpreting and making meaning of knowledge can develop more exhaustively. The content of the observations made the researchers eager to see how one could improve the quality of students' knowledge of English. This was because the researchers thought traditional processes in education might be too exhausting to follow for learners. In a nutshell, this study had scrutinized whether visualization had any positive effect on learners' foreign language learning and in this context, oral proficiency.

\section{Definition of key terms}

In this section, a list of terminologies that appear in this study is presented alphabetically to help the reader develop a more comprehensive understanding of technical terms.

\subsection{Ethnography}

A branch of anthropology concerned with the detailed descriptive study of living. As a research methodology, ethnographic research deals with prolonged direct observation, especially participant observation, attempting to see social actions and the activities of daily life from participants' point of view resulting in a long detailed description of what has been observed [12].

\subsection{Foreign Language}

[12] It is a language other than the indigenous language of a large number of native people in a particular country (p.206). It should be noted that the term "foreign language" is used by the researchers because Iranian learners in educational settings are learning another language which cannot be called second language because they do not have exposure to English outside classroom setting.

\subsection{Holistic Theory}

Holistic theory is concerned with wholes rather than parts. [4] Noted that holistic education focuses on the most possible development of the person, encouraging individuals to become the very best that they can be and enabling them to experience all they can from life and reach their goals.

\subsection{Oral Proficiency}

Oral proficiency includes the ability to communicate verbally in a functional and accurate way in the target language. It involves having the ability to apply the 'linguistic knowledge to new contexts and situations [9]. To give a more comprehensive view,[5] added "effective oral communication is all about conveying the message to other people clearly and unambiguously. It's also about receiving information that others are sending with as little distortion as possible (p. V)"'. In terms of applicability, the second definition is closer to what the researchers are trying to work on and offers a more wholesome grounding for this study.

\subsection{Self (redirected from Personal self)}

The notion of "self" as offered in this study is distant from its popular standing in the public eye. It is an aspect of personality that consists of a person's 
view of their own identity and characteristics (Richards \& Schmidt, 2007, p.474).

\subsection{Self-Awareness}

Self-awareness focuses on what is going on in one's own interior. It helps people recognize their talents, purposes and directions. From [6] point of view Self-awareness can be considered as a "stagelike process". In another place he cited that this process is "the awareness of the behavioral habits, emotions, desires, thoughts and images that tumble through our being". As a consequence, being selfaware can give one the opportunity and freedom to change those things they want to change about them and create the life that they want.

\subsection{Transpersonal self}

According to Scotton, the concept originates from the field of transpersonal psychology and has been introduced by Maslow. Transpersonal, meaning beyond the personal, refers to development beyond conventional, personal or individual levels. More specifically, it refers to development beyond the average [7].

\subsection{Visualization}

Visualization is a procedure by which one can easily replace negative beliefs with positive ones. In order for the people to eliminate already negative beliefs and replace them with new, positive ones, they should practice it constantly because it does not happen overnight. By the help of visualization even new negative thoughts are prevented to enter [2]. A complementary notion would be that visualization includes a body of positive mental images which make dreams and goals come true [13].

\section{Significance of the study}

Carl Rogers (as cited in [15], posited that the human nature becomes increasingly trustworthy when one feels at a deep level that their subjective experience is respected and progressively understood. As this research has to do with the innovative techniques for teaching and learning foreign language, its outcome can pave the ground for the growth of learners. Its emphasis is on liberating inspirations rather than restricting instructions. As a consequence, learners have freedom of speech, and they are not afraid of adding their own comments to teachers' unidirectional lectures and teachers have the essence and tolerance of hearing learners' ideas in their classes and this may not happen unless ELT teachers implement revolutionary techniques and bridge the current gap.
If Iranian educational systems are armed with holistic curriculum, teachers may become aware of teaching impacts and try to teach learners the language of human's heart and the language of human relationships which has been less addressed so far. Self-awareness was the other feasible outcome of this research by which students could be fully aware of their beliefs, personalities, values, and tendencies. The charity-affiliated participants in this study had the problem of being disregarded and the researchers probed how visualization - one of the dimensions of holism - could integrate both mind and body in a way that they feel respected so that their abilities toward foreign language might flourish, especially as regards oral proficiency.

As an experimenting teacher of English, the researchers had always been wondering if there were certain ways in which one could enhance and improve the quality and status of English as a foreign language, particularly oral proficiency in Iran. Teaching English in Iranian educational context is often restricted to pre-planned curriculum and learners are treated almost as empty vessels to be filled fully with the information they receive from their teachers who have all-out authority and control in the classroom. This helped the researchers realize the important facts that they were often unrecognized and overlooked in educational contexts at least as far as she could observe. As [8] in his book articulated, knowledge is not static but instead it relies on our ability to interpret and make meaning and this cannot happen unless knowledge and imagination are interconnected. By linking knowledge and imagination we enliven knowledge and ground the imagination in specific context (p.4). Having said all the above, through visualization as one of the techniques of imagination, both interpreting and making meaning of knowledge can develop more exhaustively. The content of the observations made the researchers eager to see how one could improve the quality of students' knowledge of English. This was because the researchers thought traditional processes in education might be too exhausting to follow for learners. In a nutshell, this study had scrutinized whether visualization had any positive effect on learners' foreign language learning and in this context, oral proficiency.

\section{Purpose of the Study}

The basis of visualization is to understand data, and to convey information not just pretty pictures. Via imagination participants benefit from using their inspiration and creativity, which have helpful effect on their foreign language learning and this cannot be fulfilled unless the teacher creates authentic relationships with his/her learners in the light of holistic approach. Holistic visualization encourages learners to think they are some other entities, so that 
it may improve their imagination and may cause them to do their utmost in expressing ideas and to make decisions. Applying the humane principle of holistic education for the purpose of enhancing learning and reducing friction among learners is the point that the researchers were following in approaching this study. The main purpose of this investigation was to explore whether oral proficiency could be enhanced by asking students to visualize different things and talk about their feelings freely.

\section{Research questions}

By virtue of this study, the reader will be expected to gain comprehensive mastery over the discussed issues in as much as this research made a determined attempt to seek appropriate answers to the following questions:

1. In what ways does holistic visualization change charity teen learners' overall view towards life?

2 . How do charity teen learners use their imagination in producing foreign language?

3. In what ways is charity teen learners' oral proficiency affected by holistic visualization?

The researchers try their best to answer these questions in her teaching and through this research; however, the explorative nature of qualitative research may let her discover ways beyond her expectation.

\section{Review of the related literature}

This part starts with the discussion of the origins and history of holistic education which is deeply rooted in the time between 1960 and 1980-a significant cultural turning point - in America. The birth of holism dates back to the time when creativity, experimentation, revolution and integration took place. It was a time when thousands of young people delved into the meditative traditions of Asia notably Buddhism and schools of yoga. At the same time human thought and imagination revived into the new world which was introduced by science and technology. Human potential and unfamiliar states of consciousness became the central focus and new ideas about education, the authority of schools and teachers, permeated.

Out of these historical contexts a philosophy known as holism / holistic education came into light. Holism means recognizing that no one view can take in the whole picture. It considers an inner core that lies beyond the physical, social, and other sources of personality that can be called the "spiritual". The term holistic education enjoyed comeback 1979. Despite the fact that the ultimate purpose of it is to transform the way that people look at themselves and their relationship to the world from a fragmented perspective to an integrative perspective, it lacks a single definition but may be described through a number of recurrent themes that appear in the literature. Among many aspects of holistic education, visualization is the one which the researchers are dealing with. Generally speaking, visualization is the graphical display of information. The major objective of any visualization in educational setting is to make the learning of some ideas, concepts, and facts easier. Segenchuk (n.d.) asserts that: In order to accomplish visualization, connections between knowledge the learner has and the knowledge being taught must be made. As a consequence, to know what the learner knows is compulsory in order to have effective visualization especially in the context of education.

The researchers have brought their own idiosyncratic term "Holistic Visualization" to teaching English. In her own idea these two terms supplement each other due to the fact that holistic psychology takes us through our inner world (self) and visualization paints the picture of one from an appropriate perspective.

Holistic visualization helps pupils to see their inner self and different aspects in them which can lead to perspective transformation, and this can be surfaced through oral proficiency. In the literature dealing with language learning, one comes across numerous references to the concept of oral proficiency.

The early history of oral proficiency is traceable to the audio lingual methodologies in the 1960s and the communicative competence movement that began in the 1970s.

The development of oral proficiency is one of the most important aspects of language learning. From among many researchers, [3] emphasized on the pressing need for English oral communication skills in various contexts which plays strong role in large number of studies carried out on oral proficiency.

\section{Methodology}

"Qualitative research played a fabulous role in this research which grounds in the world of experience. It focuses on context, and it sees social phenomena holistically [7]." Qualitative research consists of describing people, particular situations, meanings and experiences. In a similar vein, ethnography, as an offshoot of the qualitative camp, is based on observing participants in their natural environment rather than in a formal research setting. Most importantly, it allows the researchers to see behaviors in a real world context. It need be noted that in this research, providing true connection, compassion and empathy was essential.

To answer research questions, students 'oral performance was assessed. To this end, data was collected through three major techniques: such as 
observation, students' portfolios (containing their drawings, and English writings) their drawings and English writings) creating images, diagrams, animations, dramas, and interviews. For canvassing data in a more exhaustive way, still photography, video footage, and audio tracks were used. Moreover, the researchers reflected on other behaviors of the participants.

\section{Results and Discussion}

In order to describe the process of this research, I carefully listened to the recordings I had made every session, and hit upon the fact that the learner's rate of delivery had increased with regard using some prefabricated patterns. There was also some improvement in their lexical knowledge. To elaborate on the idea, one session I asked them what they liked to if they were not a human. Interestingly, they managed to recall such words as "rain", "bird", and "flower". They learned the words with their hearts. One session we played the "bottle game" during which they learned the concepts "truth and courage". On another occasion, I asked them to close their eyes and imagine that someone is giving them a ticket to whichever country they wished to go. They quickly learned the names of different countries such as Russia, Greece, the U.S.A, Germany, and Brazil. What is more, pictures with the topics like collaboration work and cell phone usage were shown to them. This helped them to learn the words related to these topics.

Through different activities, such as drama, Creating images, Diagrams, and Animations, participants were able to envision their desired future unlike their first vision at the very beginning of the class and their vision was integrated.

Furthermore, on my own side when I look back at my work, I find it a great chance for my personal growth

\section{Conclusion}

In this study, the researchers intended to realize principles of holistic education and captured students move toward better learning in oral proficiency.

Holistic visualization was merely our own idiosyncratic term about only one application of holistic education principle in EFL in special context and special time in our life. The researchers tried their best to capture it through different activities such as drama in which participants play different roles and they reflected their own experiences so beautifully. In these activities participants attempted to express without being worried to make mistake in their speaking and it engaged their imagination and creativity and facilitated their learning. Finally, through these activities participants envision their desire future unlike their first vision at the very beginning of the class and their vision was integrated. By the way it engaged learner's linear thinking and intuition.

Furthermore, on her own side when the researcher looks back at her work, she finds it a great chance for her personal growth.

\section{Acknowledgement}

I would like to highlight the point that this is thoroughly a team work effort and we couldn't have pulled it off if it wasn't for Dr. Ameri's kind support and golden help and guidelines. I thank Dr. Ghafar Tajalli a professor at Islamic Azad University, Science and Research Branch Fars, Iran for his support who has assisted to bring this paper to an end. And I would like to have a very high regard for my classmate Fatemeh Mohammad Jafari who helped a lot to accomplish all we set out to do.

\section{References}

[1] Ahoniemi,T., Lahtinen, E.(2007). Visualizations in Preparing for Programming Exercise Sessions, Electronic.www.elsevier.com/locate/entcs

[2] Betterini, W. (2001).Visualizing a Better Self-Image, retrieved from SuccessConsciousness.com, http://www.WingsForTheHeart.com.

[3] Birjandi, P. (2011).From Face-to-Face to Paired Oral Proficiency Interviews:The Nut is Yet to be Cracked, English Language Teaching Vol. 4, No. 2

[4] Hare, J. (2010).Holistic education: An interpretation for teachers in the IB programs, International Baccalaureate Organization.

[5] Jendli, A., Combe, C. \&Miled, N. (Eds.) (2010).Developing oral skills in English: Theory, Research and Pedagogy, Dubai: TESOL Arabia Publication, P.V.

[6] Jordan, T. (2001). Self-awareness, meta-awareness and the witness self, Developing awareness of ego processes, written in $2001 \mathrm{http}: / / \mathrm{www}$. perspectus.se/tjordan.

[7] Koppensteiner, N. (2007). The Art of the Transpersonal Self Transformation as Aesthetic and Energetic Practice,

[8] Miller, R. (2000).A brief introduction to holistic education, paths of learning

[9] Miller, P.J. (1988). Holistic Curriculum, Revised and Expanded Edition, the Ontario for Studies in Education. OISE press, pp.4, 12.

[10] Omaggio, H. A. (1986). Teaching language in context: Proficiency- oriented instruction.

[11] Omaggio, H. A. (1993). Teaching Language in Context, p.283. 
[12] Richards, J. C. \&Schmidt, R. (2007). Applied Linguistics, pp.474, 206,187.

[13] Sasson, R. (2001). Creative Visualization, Journal of Human Resources.

[14] Schreiner, P. (2010). The Spiritual Dimension in Holistic Education, Conference on September 10th/11th 2010, schreiner@comenius.de.

[15] Smith, M, K. (2004).Carl Rogers, core conditions and education, the encyclopedia of informal education.

[16] Stein, M. (1999).Developing Oral Proficiency in the Immersion Classroom, The Bridge: From Research to Practice. 